\title{
Mutations in the quinolone resistance determining region in Staphylococcus epidermidis recovered from conjunctiva and their association with susceptibility to various fluoroquinolones
}

\author{
M Yamada, J Yoshida, S Hatou, T Yoshida, Y Minagawa
}

Division for Vision Research, National Institute of Sensory Organs, National Tokyo Medical Center, Tokyo, Japan

Correspondence to:

Dr M Yamada, Division for Vision Research, National Institute of Sensory Organs, National Tokyo Medical Center, 2-5-1 Higashigaoka, Meguro-ku, Tokyo 152-8902, Japan; yamadamasakazu@kankakuki. go.jp

Accepted 10 April 2008
This paper is freely available online under the BMJ Journals unlocked scheme, see http:// bjo.bmi.com/info/unlocked.dtl

\begin{abstract}
Background: Staphylococcus epidermidis is one of the prominent pathogens in ocular infection. The prevalence of mutations in the quinolone resistance determining region (QRDR) area in S epidermidis isolated from the ocular surface and its association with fluoroquinolone resistance has not been fully elucidated.
\end{abstract}

Methods: Mutations in the QRDR of gyrA, gyrB, parC, and parE genes of 138 isolates of $S$ epidermidis recovered from the human conjunctival flora were analysed. The minimal inhibitory concentrations (MICs) of four fluoroquinolones (levofloxacin, gatifloxacin, moxifloxacin and tosufloxacin) against these isolates were also determined using agar dilution methods.

Results: The $\mathrm{MIC}_{90}$ values of levofloxacin, gatifloxacin, moxifloxacin and tosufloxacin were 3.13, 1.56, 0.78 and $3.13 \mu \mathrm{g} / \mathrm{ml}$, respectively. The MIC values of all fluoroquinolones showed a bimodal distribution (susceptible strain and less susceptible strain). Mutations with amino acid substitution in the QRDR were present in 70 (50.7\%) isolates. 19 different combinations of mutations were detected: 3 isolates (2.2\%) had four mutations, 8 (5.8\%) had three mutations, $43(31.2 \%)$ had double mutations and $16(11.6 \%)$ had single mutations. Isolates with mutations in the QRDR of both gyrA and parC $(n=53)$ were less susceptible to fluoroquinolones.

Conclusions: The present findings show that approximately half the $S$ epidermidis isolates from the normal human conjunctiva have mutation(s) in the ORDR. The presence of mutations in both gyrA and parC is strongly associated with reduced susceptibility to fluoroquinolones.

Staphylococcus epidermidis is one of the most prominent causes of conjunctivitis, keratitis and endophthalmitis. ${ }^{1-8}$ Although the relative frequency of different organisms as causative agents in keratitis varies during different periods and in different geographical regions, $S$ epidermidis is among the most frequently encountered organisms in clinical studies conducted in the USA, Germany and Japan. ${ }^{3-5}$ It is the most common bacterial isolate in most large studies of acute postoperative endophthalmitis. ${ }^{78}$

The fluoroquinolones are the newest family of antibacterial agents used in the treatment of ocular infections. ${ }^{239-11}$ In Japan, ofloxacin was the first fluoroquinolone introduced for topical ophthalmic use in 1987. Since then, six other fluoroquinolones-norfloxacin, lomefloxacin, levofloxacin (LVFX), gatifloxacin (GFLX), tosufloxacin (TFLX) and moxifloxacin (MFLX) have been approved for clinical use as eye drops in Japan. In addition to these compounds, ciprofloxacin has been used clinically in other countries. Their bactericidal activity against the most frequently observed Gram-positive and Gramnegative ocular pathogens is generally excellent and their high potency has made them a common choice for the treatment and prevention of ocular infections.

However, as with other antibiotic agents, continued use in a population raises the issue of emerging resistance. ${ }^{12-14}$ Since the introduction of fluoroquinolones for ophthalmic use, the reported incidence of in vitro resistance to fluoroquinolones in bacteria isolated from cases with bacterial keratitis and endophthalmitis has been steadily increasing. A previous study reviewed the database of bacterial flora cultured from the conjunctival sac of 1455 Japanese patients scheduled for intraocular surgeries between 1995 and 2002. ${ }^{14}$ The incidence of in vitro resistance of bacterial isolates to ofloxacin increased from 13.5\% in 1995 to 32.8\% in 1999. Moreover, when ofloxacin was replaced by LVFX in 2000, the incidence of resistance to LVFX gradually increased from $14.5 \%$ in 2000 to $20.5 \%$ in 2002.

The primary targets of fluoroquinolones are two essential enzymes of bacterial cells, DNA gyrase and topoisomerase IV. ${ }^{15-17}$ In $S$ epidermidis, DNA gyrase is composed of the GyrA and GyrB subunits encoded by the gyrA and gyrB genes, respectively. Topoisomerase IV is composed of ParC and ParE subunits encoded by parC and parE genes, respectively. In most bacterial species, mutations occur in the highly conserved quinolone resistance-determining regions (ORDR) of the genes that encode DNA gyrase and topoisomerase IV. In Staphylococcus aureus, several studies have shown that a combination of mutations in both genes can cause high-level resistance even to the newer fluoroquinolones. ${ }^{18-21}$ However, the prevalence of mutations in the ORDR in $S$ epidermidis isolated from the ocular surface and its association with fluoroquinolone resistance have not been fully investigated. ${ }^{15-17}$ The present study analysed mutations in the ORDR of gyrA, gyrB, parC and parE genes of 138 isolates of $S$ epidermidis recovered from conjunctival flora. The susceptibility of these isolates to LVFX, GFLX, MFLX and TFLX was also determined. 
Table 1 Primers used in the study. Nucleotide positions are indicated according to GenBank sequence number NC 002976 (S epidermidis RP62A)

\begin{tabular}{|c|c|c|c|}
\hline Target gene & Primer sequence $\left(5^{\prime}\right.$ to $\left.3^{\prime}\right)$ & $\begin{array}{l}\text { Product size } \\
\text { (bp) }\end{array}$ & Position \\
\hline \multirow[t]{2}{*}{ gyrA } & ATGCGTGAATCATTCTTAGACTATGC & 284 & $2609699-2609724$ \\
\hline & GAGCCAAAGTTACCTTGACC & & $2609441-2609460$ \\
\hline \multirow[t]{2}{*}{ gyrB } & CAGCATTAGACGTTTCAAG & 251 & $2610508-2610528$ \\
\hline & ССAATACCCGTACCAAATGC & & $2610278-2610297$ \\
\hline \multirow[t]{2}{*}{ parC } & TCGCAATGTATTCAAGTGGG & 197 & $939185-939204$ \\
\hline & ATCGTTATCGATACTACCATT & & $939361-939381$ \\
\hline \multirow[t]{2}{*}{ parE } & AAGCTCAACAAGCACGCGAGGCTG & 324 & $938196-938219$ \\
\hline & TTAAAGTCAGTACCAACACCAGCAC & & $938493-938520$ \\
\hline
\end{tabular}

\section{METHODS}

\section{Bacterial isolates and susceptibility testing}

One hundred and thirty-eight isolates of $S$ epidermidis were collected from the conjunctival sac of 138 eyes of 129 patients who were scheduled for intraocular surgery at the National Tokyo Medical Center between November 2004 and June 2005. The mean (SD) age of the patients was 70.7 (14.9) years (range 6-91 years). The patients had not received either ophthalmic or systemic antibiotics prior to bacterial sampling.

Scrapes of the inferior conjunctival fornix were taken in the absence of topical anaesthetic using a sterile cotton swab. The samples were immediately inoculated into Mueller-Hinton $(\mathrm{MH})$ agar and incubated at $35^{\circ} \mathrm{C}$ in air for $16-20 \mathrm{~h}$ for the selection of staphylococci. The MicroScan WalkAway-96 (Baxter Japan, Tokyo) with MicroScan Rapid Pos Combo Panel (Baxter) was used for the identification of $S$ epidermidis. Positive cultures were stored at $-80^{\circ} \mathrm{C}$ until the agar dilution testing to determine the minimum inhibitory concentration (MIC).

MICs for LVFX, GFLX, MFLX and TFLX were determined by the agar dilution method in accordance with the recommendations of the Japanese Society of Chemotherapy. ${ }^{22}$ The bacterial suspensions in saline were inoculated on $\mathrm{MH}$ agar plates supplemented with defined concentrations of drugs. The plates were incubated at $35^{\circ} \mathrm{C}$ under aerobic conditions and MICs were determined after 20-24 h of incubation. Drug concentrations ranged from $0.025 \mu \mathrm{g} / \mathrm{ml}$ to $100 \mu \mathrm{g} / \mathrm{ml}$ in twofold increments except for TFLX $(0.025 \mu \mathrm{g} / \mathrm{ml}$ to $25 \mu \mathrm{g} / \mathrm{ml})$ because of its limited solubility.

\section{DNA amplification and sequencing of ORDR}

The isolates were suspended in tryptic soy broth and cultured overnight. Genomic DNA was extracted using the Wizard SV 96 genomic DNA purification system (Promega KK, Japan). One $\mu 1$ of the genomic DNA solution was applied in $20 \mu \mathrm{l}$ of amplification mixture (5 pM each primer, $1.6 \mu \mathrm{dNTP}$ mixture, $2 \mu \mathrm{l}$ Ex Taq buffer and $0.1 \mu \mathrm{L}$ LA Taq (Takara Bio Inc, Japan)). Polymerase chain reaction (PCR) amplification was performed with the primers as shown in table 1. PCR primers were selected from the published sequences of $S$ epidermidis RP62A. Each reaction was amplified with the following temperature profiles: 30 cycles at $94^{\circ} \mathrm{C}$ for $30 \mathrm{~s}, 55^{\circ} \mathrm{C}$ for $30 \mathrm{~s}$ and $72^{\circ} \mathrm{C}$ for $1 \mathrm{~min}$. The amplified DNA products were separated and identified by $2 \%$ agarose gel electrophoresis.

PCR products were purified using ExoSAP according to the manufacturer's instructions (GE Healthcare Bio-Sciences KK, Japan). PCR-amplified DNA was sequenced by the dye

Table 2 Mutations in the quinolone resistance determining regions of gyrA, parC and parE in 70 strains of Staphylococcus epidermidis

\begin{tabular}{|c|c|c|c|c|c|}
\hline \multirow{2}{*}{$\begin{array}{l}\text { Mutation } \\
\text { type }\end{array}$} & \multirow{2}{*}{$\begin{array}{l}\text { No of } \\
\text { isolates }\end{array}$} & \multicolumn{4}{|l|}{ Mutation } \\
\hline & & gyrA & gyrB & parC & parE \\
\hline 1 & 28 & Ser84Phe & - & Ser80Tyr & - \\
\hline 2 & 1 & Ser84Phe & - & $\begin{array}{l}\text { Ser80Tyr + Asp84Val + } \\
\text { Ala85Ser }\end{array}$ & - \\
\hline 3 & 4 & Ser84Phe & - & Ser80Phe & - \\
\hline 4 & 4 & Ser84Phe & - & Ser80Phe + Asp84Tyr & - \\
\hline 5 & 1 & Ser84Phe & - & Ser80Phe + Asp84Asn & - \\
\hline 6 & 2 & Ser84Phe & - & Asp84Tyr & - \\
\hline 7 & 5 & Ser84Tyr & - & Ser80Phe & - \\
\hline 8 & 3 & Ser84Tyr & - & Ser80Phe & Asp434Asn \\
\hline 9 & 1 & Ser84Tyr + Glu88Lys & - & Ser80Phe + Asp84Ala & - \\
\hline 10 & 2 & Ser84Tyr & - & Ser80Tyr & - \\
\hline 11 & 1 & Ser84Tyr & - & Ser80lle & - \\
\hline 12 & 1 & Ser84lle & - & Ser80Phe & $\begin{array}{l}\text { Asn404Ser + } \\
\text { Asp434Asn }\end{array}$ \\
\hline 13 & 1 & - & - & Ser80Tyr & Asn404Ser \\
\hline 14 & 1 & - & - & Ser80Phe & - \\
\hline 15 & 1 & - & - & Asp69Asn & - \\
\hline 16 & 1 & - & - & Ser81Pro & - \\
\hline 17 & 1 & - & - & Asp84Gly & - \\
\hline 18 & 11 & - & - & - & Asn404Ser \\
\hline 19 & 1 & - & - & - & Asp434Asn \\
\hline
\end{tabular}


Table 3 Susceptibility of strains of $S$ epidermidis to four fluoroquinolones

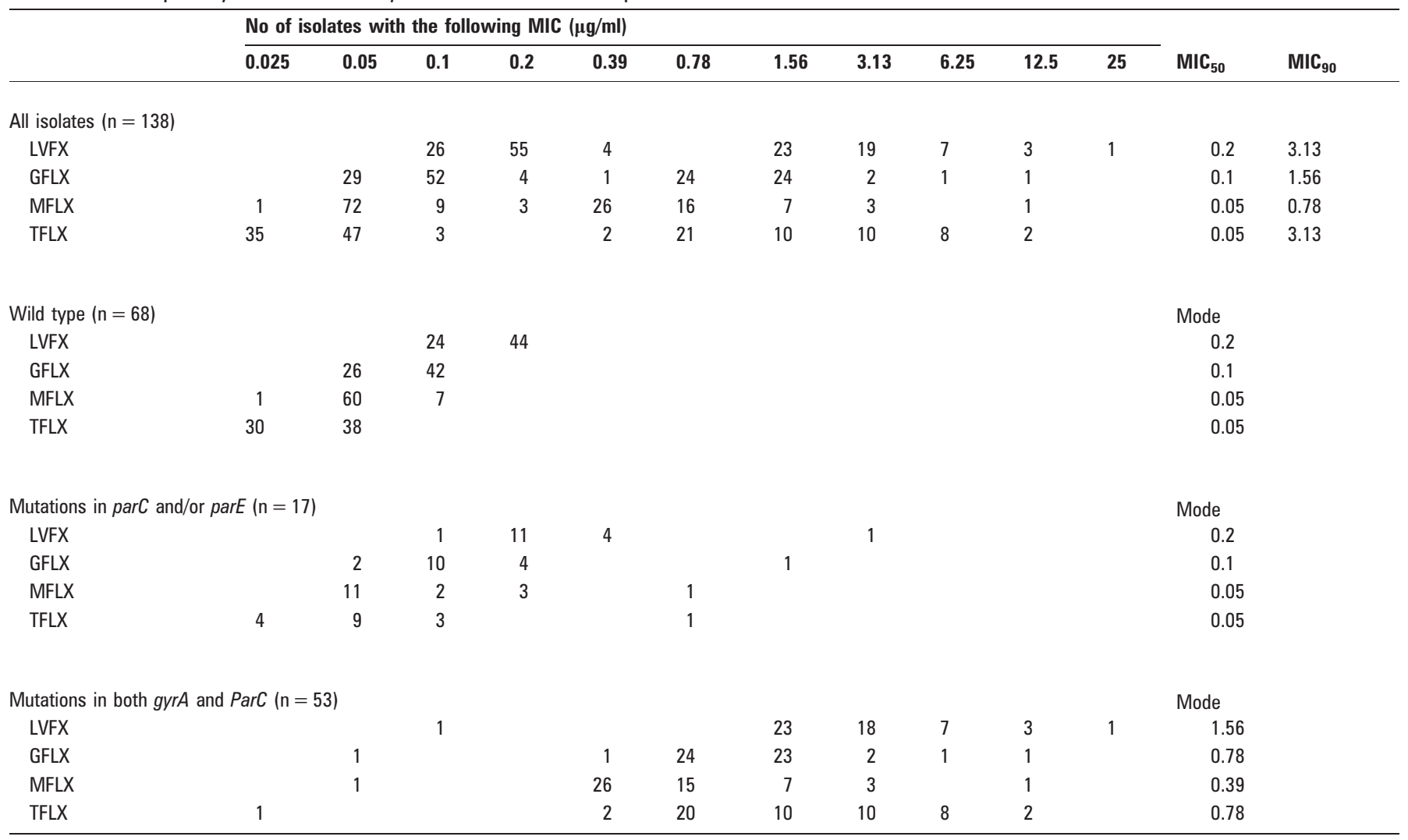

GFLX, gatifloxacin; LVFX, levofloxacin; MFLX, moxifloxacin; TFLX, tosufloxacin.

terminator method in both the forward and reverse directions. Using Phred/Phrap/Polyphred software, the quality score of each base was calculated. Sample sequences were compared with a reference sequence and mutations were detected. The strain S epidermidis ATCC 35984 (RP62A) was used as a reference.

\section{RESULTS}

The mutations identified in the ORDR of the gyrA, gyrB, parC and parE genes are summarised in table 2 . Nineteen different combinations of mutations were identified in 70 isolates, whereas no mutations were detected in 68 isolates. Three isolates (mutation profile type 2, 9 and 12) had four amino acid substitutions, 8 isolates (mutation profile type 4, 5 and 8 ) had three amino acid substitutions, 43 isolates (mutation profile type 1, 3, 6, 7, 10, 11 and 13) had double amino acid substitutions and 16 isolates (mutation profile type 14-19) had single amino acid substitutions.

In the gyrA gene, a single-point mutation was found in 53 isolates at codon 84. Double-point mutations in the gyrA gene were identified in 1 isolate at codons 84 and 88 (mutation profile type 9). No mutations were found in the ORDR area of the $g y r B$ gene. In the parC gene, single-point mutations were found in 51 isolates at codons $69,80,81,84$ or 85 . Double-point mutations were identified in 6 isolates at codons 80 and 84 (mutation profile type 4, 5 and 9). Triple-point mutations were identified in 1 isolate at codons 80,84 and 85 (mutation profile type 2). In the parE gene, single-point mutations were found in 16 isolates at codon 404 or 434 . Double-point mutations were identified in 1 isolate at codons 404 and 434.

The MICs of the four tested fluoroquinolones against $S$ epidermidis are shown in table 3 . All four fluoroquinolones had a bimodal distribution in all isolates $(\mathrm{n}=138)$. Isolates with no mutations in the ORDR (wild type; $n=68$ ) were susceptible to fluoroquinolones. The modes (the number that appears the most) were $0.2 \mu \mathrm{g} / \mathrm{ml}$ for LVFX, $0.1 \mu \mathrm{g} / \mathrm{ml}$ for GFLX, $0.05 \mu \mathrm{g} / \mathrm{ml}$ for MFLX, and $0.05 \mu \mathrm{g} / \mathrm{ml}$ for TFLX. Isolates with mutations restricted in the ORDR of parC and/or parE $(n=17)$ showed similar susceptibilities to fluoroquinolones as wild type strains except for one strain with mutation profile type 18 . The modes were $0.2 \mu \mathrm{g} / \mathrm{ml}$ for LVFX, $0.1 \mu \mathrm{g} / \mathrm{ml}$ for GFLX, $0.05 \mu \mathrm{g} / \mathrm{ml}$ for MFLX and $0.05 \mu \mathrm{g} / \mathrm{ml}$ for TFLX. Isolates with mutations in the ORDR of both gyrA and parC $(n=53)$ were less susceptible to fluoroquinolones. The modes were $1.56 \mu \mathrm{g} / \mathrm{ml}$ for LVFX, $0.78 \mu \mathrm{g} / \mathrm{ml}$ for GFLX, $0.39 \mu \mathrm{g} / \mathrm{ml}$ for MFLX and $0.78 \mu \mathrm{g} / \mathrm{ml}$ for TFLX. Of these 53 isolates, 51 had amino acid substitutions at GyrA84 and ParC80. One isolate (mutation profile type 9) with two amino acid substations both in GyrA and ParC had the highest MICs $(25 \mu \mathrm{g} / \mathrm{ml}$ for LVFX, $12.5 \mu \mathrm{g} / \mathrm{ml}$ for GFLX, MFLX and TFLX, respectively).

\section{DISCUSSION}

The primary targets of fluoroquinolones are two essential enzymes of bacterial cells, DNA gyrase and topoisomerase IV. ${ }^{18-20}$ In most bacterial species the mutations in the genes that lead to fluoroquinolone resistance are limited to a few point mutations at restricted positions of the genes called $\mathrm{QRDR}$. The present study revealed that approximately half $(50.7 \%)$ of $S$ epidermidis isolates in the human conjunctival flora have mutation(s) in the ORDR area of gyrA, gyrB, parC and parE genes.

Fluoroquinolone resistance has been studied intensively in $S$ aureus. ${ }^{18-21}$ The genes encoding topoisomerase IV in $S$ aureus are called grlA and $g r l B$, which are analogous to parC and parE in $S$ epidermidis, respectively. Fluoroquinolone resistance in $S$ aureus 
is generally associated with two single-point mutations in gyrA at codon 84, and in grlA at codon 80 or 84 . $S$ aureus isolates with higher levels of resistance are associated with the second mutation in grlA at codon 80 or 84 , depending on the position of the first mutation. When the second mutation in gyr $A$ occurs at codon 85 or 88 , in addition to the first mutation at codon 84 , the strain shows the highest fluoroquinolone resistance even to newer fluoroquinolones. ${ }^{21}$

The present $\mathrm{ORDR}$ sequencing results indicate that the major mechanism of fluoroquinolone resistance in $S$ epidermidis is analogous to that of $S$ aureus. Isolates with mutations restricted to the ORDR of parC and/or parE $(n=17)$ in this study were similarly susceptible to fluoroquinolones as wild type strains. However, the presence of two mutations $(n=53)$ in both gyrA gene (located at codon 84) and parC gene (located at codon 80) have been found to be associated with the development of fluoroquinolone resistance..$^{15} 16$

In this study only one isolate (mutation profile type 9), which was highly resistant to all four fluoroquinolones tested, had two amino acid substitutions both in GyrA and ParC. Previous studies have shown that isolates of $S$ epidermidis and $S$ aureus with two amino acid substitutions both in GyrA and ParC (GrlA in $S$ aureus) have the highest fluoroquinolone resistance. The isolates with this mutation type are reported to be relatively rare in $S$ epidermidis ${ }^{15} 16$ and to account for less than $10 \%$ in $S$ aureus. ${ }^{18-20}$ However, a high prevalence (50\%) of two amino acid substitutions in both GyrA and GrlA has recently been reported. ${ }^{21}$ The empirical use of newer fluoroquinolones without a proper clinical indication may produce additional resistant strains of $S$ epidermidis, as has already occurred with $S$ aureus.

One possible limitation of the present study was that the patients were scheduled for intraocular surgery. Bacterial isolates therefore represent conjunctival flora rather than ocular pathogens. However, in common ocular infections such as bacterial conjunctivitis and bacterial keratitis, pathogens are frequently the normal bacterial flora that reside on the ocular surface. $^{2-6}$ This is true even in cases of postoperative endophthalmitis, in which $S$ epidermidis is the most common bacterial isolate from vitreous aspirates. ${ }^{78}$ Organisms isolated from the vitreous were genetically identical to those collected from the ocular surface in $68-82 \%$ of patients with postoperative endophthalmitis, ${ }^{7}$ suggesting that the study of in vitro susceptibility to various fluoroquinolones is valid.

Drug resistance is a serious concern in treating ocular infections. The current study showed that approximately half the $S$ epidermidis isolates from the conjunctival flora have mutation(s) in the ORDR. Both gyrA gene and parC gene are associated with the development of fluoroquinolone resistance.

Funding: Supported in part by a grant from the Ministry of Health, Labour and Welfare, Japan.

Competing interests: None.
Ethics approval: The principles of the World Medical Association Declaration of Helsinki were followed. Each subject received a thorough explanation of the purpose of the study and all procedures involved in the study, and provided written informed consent prior to enrolment. Approval for this investigation was granted by the Committee for the Protection of Human Subjects at National Tokyo Medical Center.

\section{REFERENCES}

1. O'Brien TP. Bacterial keratitis. In: Krachmer JH, Mannis MJ, Holland EJ, eds. Cornea and external disease: clinical diagnosis and management. Volume II. St Louis: MosbyYear Book, 1997:1139-90.

2. Graves A, Henry M, O'Brien TP, et al. In vitro susceptibilities of bacterial ocular isolates to fluoroquinolones. Cornea 2001;20:301-5.

3. O'Brien TP, Maquire MG, Fink NE, et al. Efficacy of ofloxacin versus cefazolin and tobramycin in the therapy for bacterial keratitis. Report from the Bacterial Keratitis Study Research Group. Arch Ophthalmol 1995;113:1257-65.

4. Study Group of National Surveillance of Infectious Keratitis in Japan. National surveillance of infectious keratitis in Japan. Current status of isolates, patient background, and treatment. J Jpn Ophthalmol Soc 2006;110:961-72.

5. Frohlich SJ, deKaspar HM, Grabson T, et al. Bacterial keratitis in patients with and without contact lens anamnesis. Klin Monat Augenheilk 1999;214:211-6.

6. Bourcier T, Thomas F, Borderie V, et al. Bacterial keratitis: predisposing factors, clinical and microbiological review of 300 cases. Br J Ophthalmol 2003;87:834-8.

7. Han DP, Wisniewski SR, Wilson LA, et al. Spectrum and susceptibilities of microbiologic isolates in the Endophthalmitis Vitrectomy Study. Am J Ophthalmol 1996:122:1-17

8. Sandvig KU, Dannevig L. Postoperative endophthalmitis: establishment and results of a national registry. J Cataract Refract Surg 2003;29:1273-80.

9. Neu HC. Microbiologic aspects of fluoroquinolones. Am J Ophthalmol 1991;112(Suppl 4):S15-24.

10. Leibowitz HM. Clinical evaluation of ciprofloxacin $0.3 \%$ ophthalmic solution for treatment of bacterial keratitis. Am J Ophthalmol 1991;112(Suppl 4):S34-47.

11. Hyndiuk RA, Eiferman RA, Caldwell DR, et al. Comparison of ciprofloxacin ophthalmic solution $0.3 \%$ to fortified tobramycin-cefazolin in treating bacterial corneal ulcers. Ophthalmology 1996;103:1854-62.

12. Chalita MG, Hüfling-Lima AN, Paranhos A, et al. Shifting trends in in vitro antibiotic susceptibilities for common ocular isolates during period of 15 years. Am J Ophthalmol 2004;137:43-51.

13. Goldstein $\mathbf{M H}$, Kowalski RP, Gordon YJ. Emerging fluoroquinolone resistance in bacterial keratitis. Ophthalmology 1999;106:1313-8.

14. Kurokawa N, Hayashi K, Konishi M, et al. Increasing ofloxacin resistance of bacterial flora from conjunctival sac of preoperative ophthalmic patients in Japan. Jpn J Ophthalmol 2002;46:586-9.

15. Dubin DT, Fitzgibbon JE, Nahvi MD, et al. Topoisomerase sequences of coagulasenegative staphylococcal isolates resistant to ciprofloxacin or trovafloxacin. Antimicrob Agents Chemother 1999:43:1631-7.

16. Li Z, Deguchi T, Yasuda M, et al. Alteration in the GyrA subunit of DNA gyrase and the ParC subunit of DNA topoisomerase IV in quinolone-resistant clinical isolates of Staphylococcus epidermidis. Antimicrob Agents Chemother 1998;42:3293-5.

17. Sreedharan S, Peterson LR, Fisher LM. Ciprofloxacin resistance in coagulasepositive and -negative staphylococci: role of mutations at serine 84 in the DNA gyrase A protein of Staphylococcus aureus and Staphylococcus epidermidis. Antimicrob Agents Chemother 1991;35:2151-4.

18. Wang T, Tanaka M, Sato K. Detection of grlA and gyrA mutations in 344 Staphylococcus aureus strains. Antimicrob Agents Chemother 1998;42:23-40.

19. Hooper DC. Fluoroquinolone resistance among Gram-positive cocci. Lancet Infect Dis 2002;2:530-8.

20. Horii T, Suzuki Y, Monji A, et al. Detection of mutations in quinolone resistancedetermining regions in levofloxacin- and methicillin-resistant Staphylococcus aureus: effect of the mutations on fluoroquinolone MICs. Diagn Microbiol Infect Dis 2003;46:139-45.

21. lihara H, Suzuki T, Kawamura $Y$, et al. Emerging multiple mutations and high-leve fluoroquinolone resistance in methicillin-resistant Staphylococcus aureus isolated from ocular infections. Diagn Microbiol Infect Dis 2006;56:297-303.

22. Japanese Society of Chemotherapy. Revision of methods for determining minimum inhibitory concentrations. Chemotherapy 1981;29:76-9. 